\title{
Removal of Methylene Blue Dye from Synthetic Wastewater using Kenaf Core and Activated Carbon
}

\author{
Saleem Ethaib*"1 $^{\text {, Iqbal K. Erabee }}{ }^{2}$, Ali A. Abdulsahib ${ }^{3}$ \\ ${ }^{1,2,3}$ Civil Engineering Dept., College of Engineering, University of Thi Qar, Al-Nassiriya, Iraq \\ *Corresponding Author E-mail: salem_eidt@yahoo.com
}

\begin{abstract}
The removal of textile-based cationic methylene blue (MB) dye from synthetic wastewater was investigated in batch model using low cost agro-based adsorbents named Kenaf core, and the activated carbon. A comparative analysis between these adsorbents was defined via $\mathrm{pH}$, adsorbent dose and contact time on adsorption process, and morphological properties. In addition, isotherms adsorption studies were estimated for determination of the equilibrium adsorption capacity. The experimental observation showed that the optimum $\mathrm{pH}$ values for Kenaf core and the activated carbon were 6 and 4 respectively. Meanwhile the optimum adsorbent dosage values for Kenaf and the activated carbon were $1.5 \mathrm{~g}$ for both. The results showed that a high adsorption efficiency for Kenaf core which was about $84 \%$ and $92 \%$ for activated carbon. The correlation coefficients $\left(R^{2}\right)$ for kenaf core were equal to 0.8789 and 89 for Langmuir and Freundlich isotherm, respectively. Meanwhile, the correlation coefficients $\left(R^{2}\right)$ for activated carbon were equal were 0.8974 and 0.7643 for Langmuir and Freundlich isotherms, respectively. The results illustrated that the Kenaf core has a porous and an irregular surface area which make it a suitable adsorbent for dyes in the wastewater.
\end{abstract}

Keywords: Activated carbon; Adsorption; Kenaf core; Methylene blue; Wastewater treatment.

\section{Introduction}

The discharge of ineffectively treated effluent was increased with increasing pressure on existing wastewater treatment plants, emphasizing this subject need to improve and device more stringent methods for regulating industrial discharged effluent and freshwater sources. The chemical diversity in the organic components of these pollutants especially from textile waste contributes severely to water pollution, thus impairing the efficiencies and adeptness of different treatment processes for detoxification [1].The effluent color being is one of the most apparent indicators of water pollution. The use of synthetic chemical dyes in several industrial processes for manufacturing pulp, paper, plastics, leather and cloth poses significant threat to the ecosystem [2]. The discharge of these highly colored synthetic dye effluents such as the textile-based cationic methylene blue (MB) dye is visually invasive and can mutilate freshwater body by hindering light penetration and oxygen dissipation, crucial to sustain numerous aquatic forms.

Dyes can be defined as recalcitrant organic molecules which are impervious to biological digestion and stable to light, high temperature and oxidizing agents [3]. The presence of $\mathrm{MB}$ in wastewater is harmful for human beings, living organism and has toxic effect to microorganism's disease [4]. To overcome the difficulties associated with conventional treatment systems of wastewater, adsorption has emerged as a promising and more efficient treatment process to remove of colored organics in effluents and soils [5]. Adsorption is driven by imbalanced forces of intermolecular interaction that contributes to the surface energy enabling the preferential adherence of substrate molecules to the surface of an adsorbent material. Adsorption can either be functional in a single mode, such as removal of dyes from simulated and synthetic wastewaters, or in an interoperability mode for the treatment of actual wastewaters [6].

In recent times, several materials have been used at the third stage of effluent treatment for the removal of recalcitrant pollutants. Activated carbon is considered one of the most effective adsorbent used to remove organic and inorganic contaminations from wastewater. However, still there is concern about using the activated carbon due to cost limitation. The agriculture materials consider a favorer option in the search about feasible rout in adsorption process. Nowadays, many different types of agricultural materials used to prepare activated carbon such as sago palm park [7], date pits [8], and industrial waste products (metal hydroxide sludge, carbon waste slurries, and coffee wastes) [9]. In this study, Kenaf core was examined for its ability to remove textile-based cationic methylene blue (MB) dye from synthetic wastewater and compared to the well-known adsorbent, the activated carbon.

\section{Material and Methods}

\subsection{Materials}

The two natural adsorbents (Kenaf core and activated carbon) were used for adsorption and morphological studies, obtained from field without treatment. Kenaf core was grained and sieved while the activated carbon was used at laboratory grade. The synthetic dye employed as adsorbate in this study is the textilebased cationic methylene blue (MB) dye (MF: C16.H18.Cl.N3.S, MW: $319.85 \mathrm{~g} / \mathrm{mol}, \lambda$ : $664 \mathrm{~nm})$. MB was prepared in the concentration range of $20 \mathrm{mg} / \mathrm{L}$ to $100 \mathrm{mg} / \mathrm{L}$ from stock concentration while sodium hydroxide $(\mathrm{NaOH})$ and hydrochloric acid $(\mathrm{HCl})$ were used for $\mathrm{pH}$ adjustment (Fisher 1000-pH meter). All experimental protocols were subjected to laboratory standards 
[Drying Temperature $=60{ }^{\circ} \mathrm{C}$, Drying Temperature $=25{ }^{\circ} \mathrm{C}$, Shaker Rotation $=150 \mathrm{rpm}$, Centrifugal Speed $=3000 \mathrm{rpm}]$. The Kenaf core obtained from field were shredded into tiny fragments, and washed in distilled water thrice for dust removal. Thereafter, the Kenaf were dried in the oven at $60{ }^{\circ} \mathrm{C}$ ) for 24 hours. When the Kenaf becomes dried, it is grinded into fine particles with diameter-sized $<500 \mu \mathrm{m}$ and filtered via 200-300 $\mu \mathrm{m}$ sieves (Cole Parmer Sieve shakers) prior to its usage as adsorbent. The activated carbon was supplied from ( $\mathrm{R} \& \mathrm{M}$ chemicals, UK) at standard laboratory grade.

\subsection{Experimental Procedures}

Different concentrations $(20,40,60,80$, and $100 \mathrm{mg} / \mathrm{L})$ of $100 \mathrm{ml}$ of methylene blue were poured in $250 \mathrm{ml}$ flasks with each flask containing $500 \mathrm{mg}$ of specific adsorbent - Kenaf core or activated carbon. The optimum $\mathrm{pH}$ for $\mathrm{MB}$ removal was determined for both adsorbents at room temperature $\left(25^{\circ} \mathrm{C}\right)$. The concentration of MB dye removed via adsorption were determined with the aid of a single beam UV spectrophotometer (Thermo Scientific ${ }^{\mathrm{TM}}$ Orion ${ }^{\mathrm{TM}}$ AquaMate $^{\mathrm{TM}}$ ) at the maximum wavelength of $663 \mathrm{~nm}$. With a total experiment time of 150 minutes, sample determinations were carried out at an interval of 10 minutes. The synthetic MB dye was prepared from stock solutions with $\mathrm{pH}$ adjustment carried out by the addition of sodium hydroxide $(\mathrm{NaOH})$ and hydrochloric acid $(\mathrm{HCl})$. The optimum $\mathrm{pH}$ for the efficient adsorption of $\mathrm{MB}$ by each adsorbent (Kenaf core or activated carbon) was determined within $\mathrm{pH}$ ranges 2 to 11 . All $\mathrm{pH}$ readings were conducted using a Fisher 1000-pH meter.

The contact time experiments for the adsorption of MB dye was carried out and monitored at an interval of 10 minutes. $100 \mathrm{~mL}$ of $50 \mathrm{mg} / \mathrm{L} \mathrm{MB}$ concentrate was added to $0.5 \mathrm{~g}$ of each adsorbent (Kenaf core or activated carbon) before being subjected to shaking at room temperature $\left(25^{\circ} \mathrm{C}\right)$ with a mixing rate of $150 \mathrm{rpm}$. The adsorption efficiencies for the removal of MB dye were measured using a single beam UV spectrophotometer (Thermo Scientific ${ }^{\mathrm{TM}}$ Orion $^{\mathrm{TM}}$ AquaMate ${ }^{\mathrm{TM}}$ ).

The dosage of each adsorbent was investigated by fixing concentration of MB dye as $50 \mathrm{mg} / \mathrm{L}$. Thus, $100 \mathrm{~mL}$ of $50 \mathrm{mg} / \mathrm{L}$ MB concentrate was prepared at the predefined optimal $\mathrm{pH} 6$ (Kenaf) and $\mathrm{pH} 4$ (activated carbon), respectively. The mass dosages for both adsorbents were varied at $0.25 \mathrm{~g}, 0.50 \mathrm{~g}, 1.0 \mathrm{~g}$, and $1.5 \mathrm{~g}$. In the course of these experiments, the samples were continually monitored at an interval of 10 minutes until the equilibrium state for adsorbent saturation was attained. All experimental flasks were made up of a $100 \mathrm{~mL}$ MB dye solution at varying concentrates and $0.5 \mathrm{~g}$ mass dosage for each adsorbent. All other experimental parameters were kept constant $(150 \mathrm{rpm}$, $25^{\circ} \mathrm{C}$ ). The isotherm for the adsorption mechanism of MB dye on each adsorbent (Kenaf core or activated carbon) was determined using two isotherm models: Langmuir and Frendlich. The predefined experimental data were correlated to these two isotherm models and analyzed for suitable fit. The percentage of removal efficiency and the amount of adsorbent adsorbed at equilibrium condition, $q e(\mathrm{mg} / \mathrm{g})$, were calculated and reported.

\section{Result and Discussions}

\subsection{Maximum Absorption Wavelengths}

The maximum absorption wavelength $\left(\lambda_{\max }\right)$ for MB dye was determined as $663 \mathrm{~nm}$ after a UV-spectrophotometric scanning was conducted on the samples within the wavelength range $300 \mathrm{~nm}$ to $700 \mathrm{~nm}$. Different diluted concentrations of MB dye prepared from the $1000 \mathrm{mg} / \mathrm{L}$ stock concentrate were analyzed at $663 \mathrm{~nm}$ to define the calibration data of this textile-based cationic methylene blue (MB) dye. Fig. 1 shows the calibration curve for methylene blue at varying concentrations.

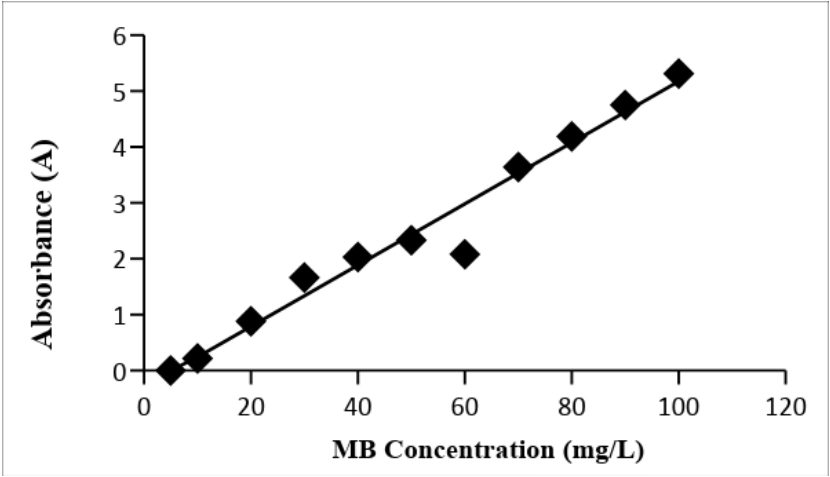

Fig. 1: Calibration Curve for Methylene Blue

\subsection{Effect of $\mathrm{pH}$ on the Adsorption of MB}

The $\mathrm{pH}$ have a significantly effect in the adsorption process. The $\mathrm{pH}$ of solution affects the surface charge of the adsorbent and the influences structural stability of methylene blue [10]. The variation in methylene blue dye adsorption with the initial $\mathrm{pH}$ was changed based on solution type for Kenaf core and activated carbon. The effect of $\mathrm{pH}$ solution has been study in the adsorption on methylene blue and the range was between 2 and 9 as shown in Fig. 2.
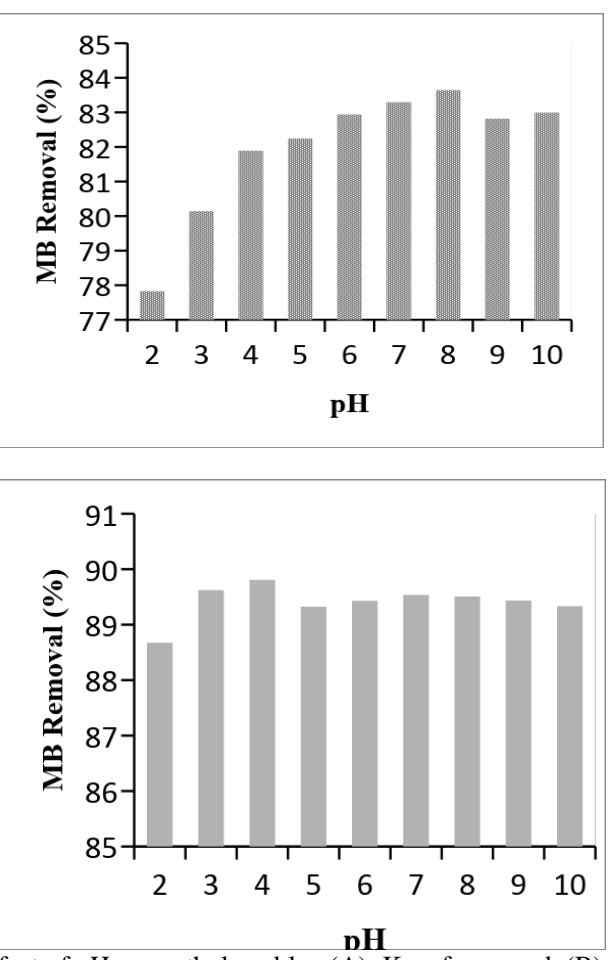

Fig. 2: Effect of $\mathrm{pH}$ on methylene blue (A) Kenaf core and (B) activated carbon

The optimum $\mathrm{pH}$ solution of Kenaf core was found to be $\mathrm{pH} 6$. The maximum adsorption of methylene blue onto Kenaf core was at $\mathrm{pH}$ 6, the optimum $\mathrm{PH}$ has used to the rest of each parameter to ensure maximum amount of adsorption. Activated carbon optimum $\mathrm{pH}$ was 4 as shown in Fig.2. The followed experiment was conducted under the optimum $\mathrm{pH}$ for both adsorbents Kenaf core and the activated carbon.

\subsection{Effect of adsorbent dosage on MB removal}

The dosage effect of adsorbent has been investigated by fixed concentration $(50 \mathrm{mg} / \mathrm{l})$ of methylene blue (MB), $150 \mathrm{rpm}$ rotating speed, $25^{\circ} \mathrm{C}$ temperature and optimum $\mathrm{pH}$ of each adsorbent. The variation of dosage was investigated for the two adsorbent dosages. The amount of adsorbed dye evaluated at equilibrium time per adsorbent mass. The effect of dosage in the adsorption of 
methylene blue onto the two adsorbents is described in Fig. 4. The amount of dye removed was $40 \mathrm{mg} / \mathrm{g}$ with $0.25 \mathrm{~g}$ Kenaf, by increasing the dosage of the adsorbent to $1.5 \mathrm{~g}$, the amount of removed dye removal was increased $42.3 \mathrm{mg} / \mathrm{g}$. This can be attributed to the increase of Kenaf dosage provided extra surface area to adsorb more dye particles. On the other hand, the Activated carbon has less respond to the increase in its dosage. The results showed that the amount of removed dye was 43.9 $\mathrm{mg} / \mathrm{g}$ at $0.25 \mathrm{~g}$ of activated carbon, meanwhile, increase the adsorbent dose to $1.5 \mathrm{~g}$ caused an increasing in amount of removed dye to $44.6 \mathrm{mg} / \mathrm{g}$ These results revealed that the superiority of activated carbon compared Kenaf which means that the activated carbon can act is very effective adsorbent even in small dosage. It is reported that one gram of activated carbon has a surface area in excess of $3,000 \mathrm{~m} 2(32,000 \mathrm{sq} \mathrm{ft})$ [11]. The adsorbent dosage of $1.5 \mathrm{~g}$ was selected to perform the following experiments.
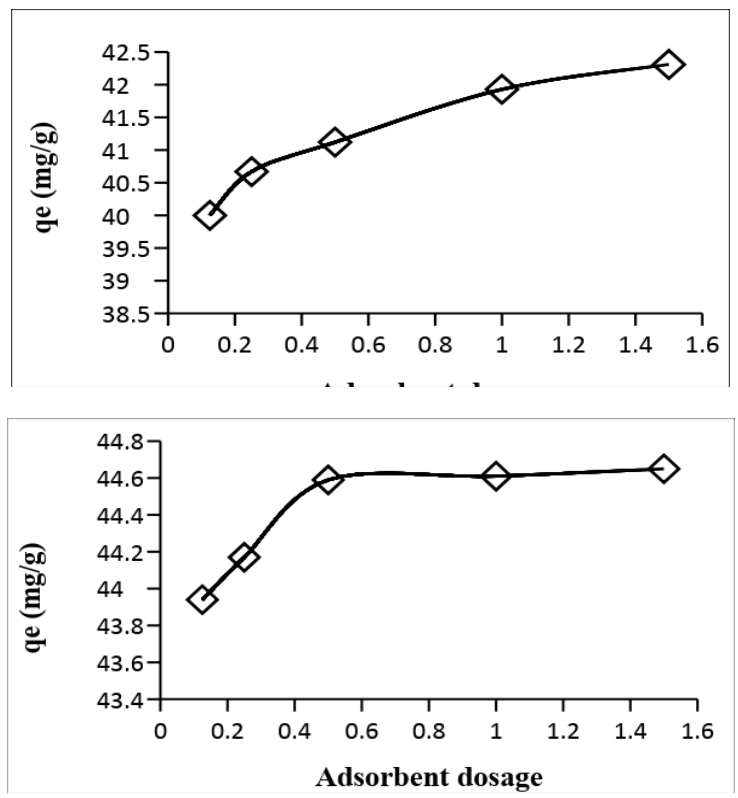

Fig. 3: Effect of Kenaf (A) and activated carbon (B) on methylene blue adsorption

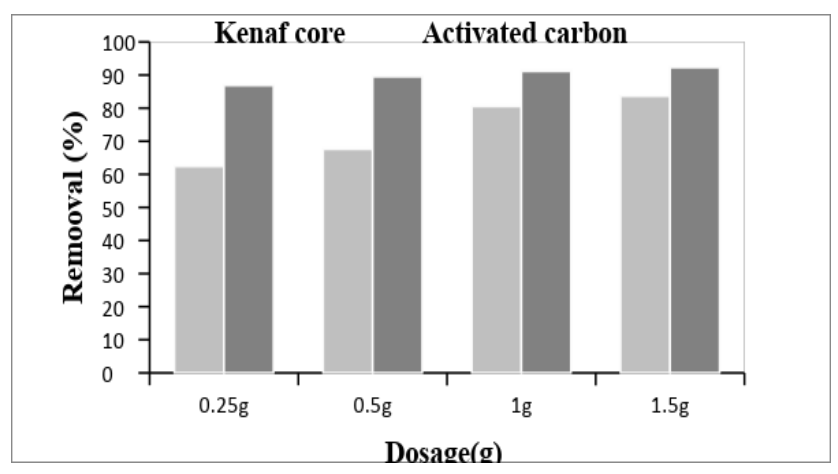

Fig. 4: Adsorption efficiency of adsorbents for MB removal based on adsorbent dosage

\subsection{Efficiency of Adsorbents}

The contact time between MB dye and the adsorbent can influence the adsorption process. Agro-based adsorbents such as Kenaf core and activated carbon were investigated to determine their removal efficiencies of MB pollutant. Fig. 5 shows the trend in the adsorption efficiencies of both adsorbents for MB removal within the duration of 2 hours. The amount of $\mathrm{MB}$ adsorbed during the studies was quantified as $\mathrm{q}_{\mathrm{e}}(\mathrm{mg} / \mathrm{g})$ of $\mathrm{MB}$ adsorbed per unit mass per time.

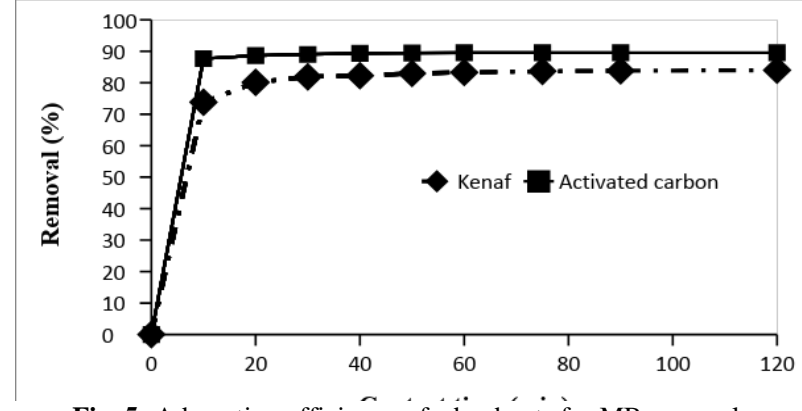

Fig. 5: Adsorption efficiency of adsorbents for MB removal

Based on the adsorption trajectories that were illustrated in Fig. 5, Kenaf core had lower affinity for MB adsorption than activated carbon, it was found that it had a $\mathrm{q}_{\mathrm{e}}$ value of $40-45 \mathrm{mg} / \mathrm{g}$ after 20 minutes; meanwhile it was $20-25 \mathrm{mg} / \mathrm{g}$ for activated carbon. It was clear that activated carbon group higher number of basic functional for aqueous system hence strongly attracts methylene blue. Activated carbon was the most effective adsorbent followed with Kenaf. In general, the adsorbents reached the equilibrium in 20 minutes for activated carbon and 60 minutes for Kenaf the result is very reasonable. The highest removal efficiency using Kenaf core and activated carbon were about $83.6 \%$ and $92.3 \%$ respectively.

\subsection{Adsorption Isotherm}

One of the most important data in adsorption process is the equilibrium adsorption isotherm. It is facilitate understanding the mechanism of the adsorption systems. Several isotherm models are available; the Langmuir and Freundlich models are two important isotherms and selected in this study.

Langmuir isotherm was used to identify if the adsorption occurs through monolayer formation. The adsorption is considers following Langmuir model if the adsorption environment is homogeneous and the value of regression coefficient $\left(R^{2}\right)$ is high. The model of Langmuir isotherm draws in linear plot based on Equation 1 [12]. All of Langmuir monolayer adsorption constant, Langmuir energy can be estimated from the slope and intercept of that equation for all of the investigated adsorbent in this study (Fig. 6). Parameters of Langmuir equation form above for the two adsorbent onto methylene below is presented in Table 1 .

ceqe $=$ ce qmax $+1 \mathrm{kl} . q \max$
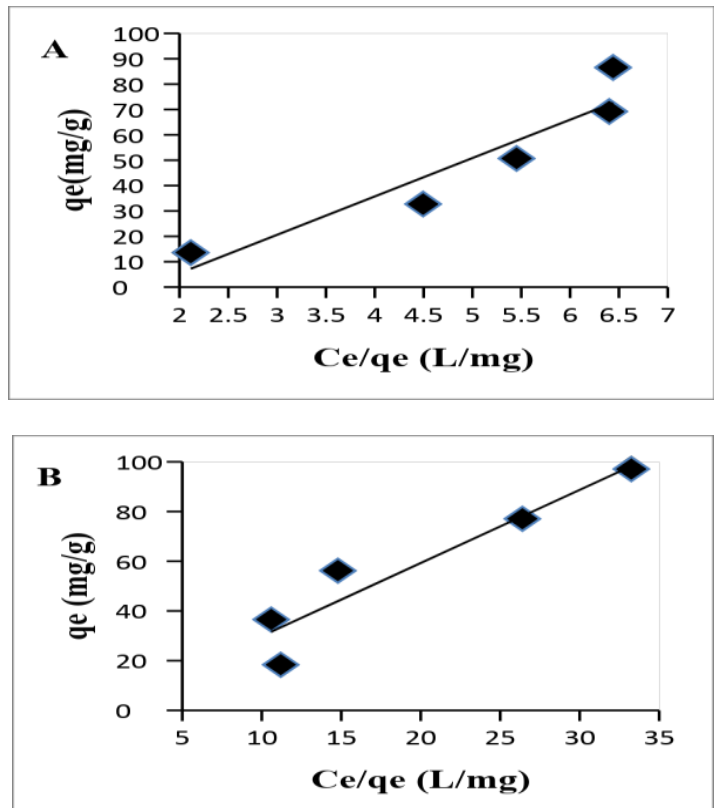

Fig. 6: (A) Langmuir isotherm of Kenafand (B) Activated Carbon 
Equation 2 an empirical equation was used to describe Freundlich isotherm model [13]. This model was designated to identify the heterogeneous systems.

$\log \mathrm{e}=\log \mathrm{Kf}+1 \mathrm{n} \log \mathrm{Ce}$

The plot of $\log \mathrm{C}_{\mathrm{e}}$ versus $\log q_{e}$ is linear with Freundlich constants ( $n$ and $\mathrm{K}_{\mathrm{f}}$ ) which can be obtained from the slop and the intercept (Fig. 7). The values of Freundlich are presented in Table 2. The correlation coefficients $\left(R^{2}\right)$ for kenaf core were equal to 0.8789 and 89 for Langmuir and Freundlich isotherm, respectively. Meanwhile, the correlation coefficients $\left(R^{2}\right)$ for activated carbon were equal were 0.8974 and 0.7643 for Langmuir and Freundlich isotherms, respectively. This revealed that the Freundlich isotherm represented the adsorption of $\mathrm{MB}$ on Kenaf core and activated carbon. It can be concluded that the adsorption process for MB was heterogeneous.
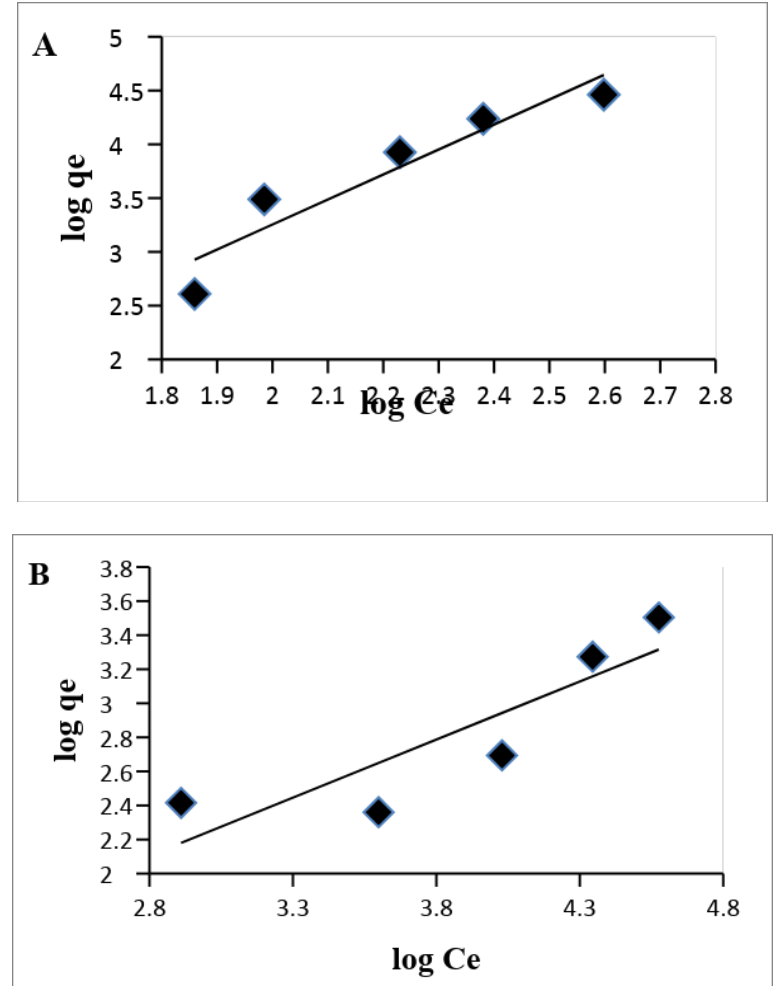

Fig. 7: Freundlich isotherm of MB (A) Kenaf core and (B) Activated carbon

Table 1: Langmuir and Freundlich Parameters

\begin{tabular}{|l|l|l|l|l|l|l|}
\hline & \multicolumn{3}{|l|}{ Langmuir constants } & \multicolumn{2}{l|}{ Freundlich constants } \\
\hline $\begin{array}{l}\text { Adsorben } \\
\mathrm{t}\end{array}$ & $\begin{array}{l}\mathrm{q} \\
(\mathrm{mg} / \mathrm{g} \\
)\end{array}$ & $\mathrm{K}_{\mathrm{l}}$ & $\mathrm{R}^{2}$ & $\mathrm{~N}$ & $1 / \mathrm{n}$ & $\begin{array}{l}\mathrm{K} \\
{\left[(\mathrm{mg} / \mathrm{g})(\mathrm{L} / \mathrm{mg})^{1 /}\right.} \\
\mathrm{n}^{1 /}\end{array}$ \\
\hline $\begin{array}{l}\text { Kenaf } \\
\text { core }\end{array}$ & 35.4 & $\begin{array}{l}0.05 \\
8\end{array}$ & 0.879 & $\begin{array}{l}0.43 \\
0\end{array}$ & $\begin{array}{l}2.32 \\
3\end{array}$ & 0.040 \\
\hline $\begin{array}{l}\text { Activated } \\
\text { carbon }\end{array}$ & 6.02 & $\begin{array}{l}0.30 \\
5\end{array}$ & $\begin{array}{l}0.897 \\
4\end{array}$ & $\begin{array}{l}1.46 \\
6\end{array}$ & 0.68 & 1.566 \\
\hline
\end{tabular}

\subsection{Scanning Electron Microscopy (SEM)}

Fig. 8 shows the surface of the Kenaf core before and after adsorption. The results illustrated that the Kenaf core has a porous and an irregular surface area which make it a suitable adsorbent for dyes. The roughness of Kenaf core surface could enhance methylene blue adsorption via increasedye particle capture and increase the available surface area for adsorption. Activated carbon is the best adsorbent due to the high surface area that it is give the activated carbon ability to adsorb more molecules of the dye. Fig. 8 shows difference between after and before the adsorption because the small surface area of activated carbon.
However, color changes on the dye solution before and after the adsorption suggested that the adsorbents have been adsorbed the methylene blue from the solution.

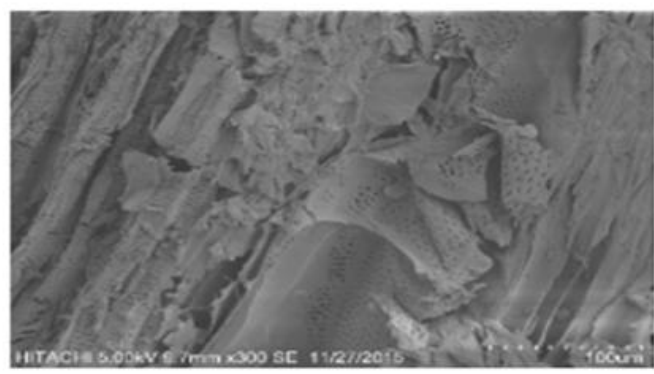

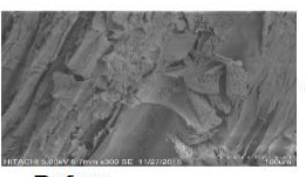

Before
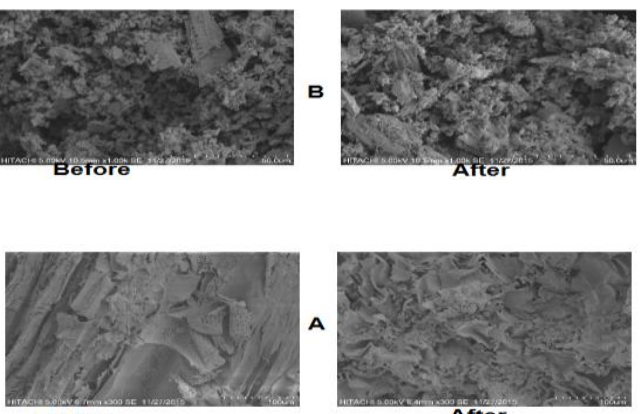

Before
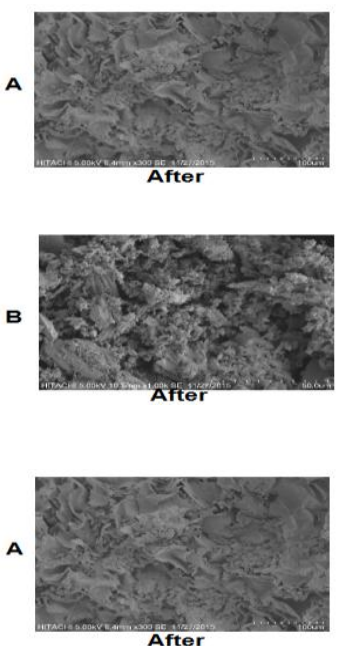

After

After

B

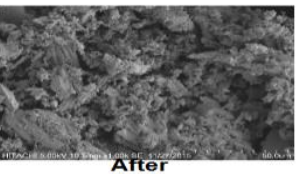

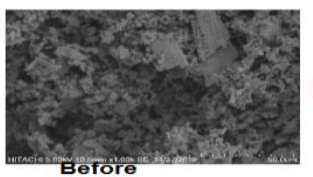

Fig. 8: SEM images, A and B for raw Kenaf and after the adsorption respectively, C and D for raw activated carbon and after the adsorption respectively

\section{Conclusion}

This study has shown possibility of Kenaf core, activated carbon for treatment of wastewaters containing dyes. Kenaf core and activated carbon all have successful in the removal of methylene blue dye from wastewater. The higher MB dye removal efficiency was for activated carbon $92.3 \%$ followed the Kenaf was $83.6 \%$ in the effect of dosage with $1.5 \mathrm{~g}$ of each adsorbent. The equilibrium data of methylene blue MB was found to be fits to the Freundlich isotherm model of Kenaf as demonstrated by high regression coefficient values for activated carbon it was followed to Langmuir. As a result, the adsorption of MB onto Kenaf core occurs over multilayer formation while activated carbon occurs in monolayer formation on the adsorbent surfaces. 


\section{Reference}

[1] Erabee IK, Ahsan A, Jose B, Arunkumar T, Sathyamurthy R, Daud NNN, Idrus S., Effects of electric potential, $\mathrm{NaCl}, \mathrm{pH}$ and distance between electrodes on efficiency of electrolysis in landfill leachate treatment, Journal of Environmental Science and Health $\begin{array}{llll}\text { (Part } & \text { A) }, 52 & \text { (8), } & \text { (2017), }\end{array}$ http://dx.doi.org/10.1080/10934529.2017.1303309

[2] Chanzu HA, Onyari JM, Shiundu PM., Biosorption of malachite green from aqueous solutions onto polylactide/spent brewery grains films: kinetic and equilibrium studies., J Polym Environ; 20 (3), (2012) $665-672$.

[3] Sun and Yang L,The adsorption of basic dyes from aqueous solution on modified peat-resin particle, Water Research, 37(7), (2003), 1535-44.

[4] Padhi, B. S., Pollution due to synthetic dyes toxicity \& carcinogenicity studies and remediation, International Journal of Environmental Sciences, 3(3), (2012), 940.

[5] Erdem, N. Karapinar and R. Donat. The removal of heavy metal cations by natural zeolites. Journal of Colloid and Interface Science, 280(2), (2004), 309-314.

[6] Erabee, I.K., and Saleem Ethaib, Treatment of contaminated Landfill Leachate using Aged Refuse Biofilter Medium, Oriental Journal of Chemistry 34, (2018), 1441-1450.

[7] Erabee, I. K., Ahsan, A., Jose, B., Aziz, M. M. A., Ng, A. W. M., Idrus, S. Daud, N. N. N., Adsorptive treatment of landfill leachate using activated carbon modified with three different methods. KSCE Journal of Civil Engineering, (2017), 1-13. https://doi.org/10.1007/s12205-017-1430-Z

[8] Erabee IK, Ahsan A, Daud NNN, Idrus S, Shams S, Md Din MF, Rezania S., Manufacture of low-cost activated carbon using sago palm bark and date pits by physiochemical activation, BioResources, $12 \quad$ (10), (2017),1916-1923. http://dx.doi.org/10.15376/biores.12.1.1916-1923

[9] Kyzas, G. Z., Lazaridis, N. K., Mitropoulos, A. C., Removal of dyes from aqueous solutions with untreated coffee residues as potential low-cost adsorbents: Equilibrium, reuse and thermodynamic approach, Chemical engineering journal, 189,(2012), 148-159.

[10] Chada, Nagaraju, Jimmy Romanos, Ramsey Hilton, Galen Suppes, Jacob Burress, Peter Pfeifer, Activated carbon monoliths for methane storage. Bulletin of the American Physical Society. In APS Meeting Abstracts. 57 (1). 2012-03-01.

[11] Elaziouti, A., N. Laouedj, B. Ahmed, Effect of $\mathrm{pH}$ solution on the optical properties of cationic dyes in dye/maghnia montmorillonite suspensions, J Chem Eng Process Technol, 2, (2011), 113-117.

[12] Wang, X. S., Zhou, Y., Jiang, Y., Sun, C. The removal of basic dyes from aqueous solutions using agricultural by-products. Journal of Hazardous Materials, 157(2-3), (2008), 374-385.

[13] Weber, T. W., and Chakravorti, R. K., Pore and solid diffusion models for fixed-bed adsorbers. AIChE Journal, 20(2), (1974), 228-238. 